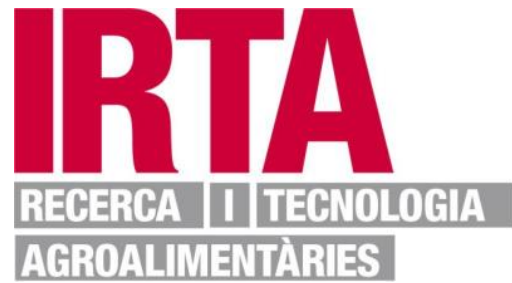

This is the peer reviewed version of the following article: Lafarga, Tomás, Carlos Álvarez, Silvia Villaró, Gloria Bobo, and Ingrid Aguiló-Aguayo. 2019. "Potential of Pulse-Derived Proteins For Developing Novel Vegan Edible Foams And Emulsions". International Journal Of Food Science \& Technology 55 (2): 475-481. doi:10.1111/ijfs.14286, which has been published in final form at https://doi.org/10.1111/ijfs.14286. This article may be used for non-commercial purposes in accordance with Wiley Terms and Conditions for Use of Self-Archived Versions http://www.wileyauthors.com/self-archiving.

Document downloaded from: 


\title{
Potential of pulse-derived proteins for developing novel vegan edible foams and emulsions
}

Lafarga, T. ${ }^{\text {a }}$, Álvarez, C. ${ }^{\mathrm{b}}$, Villaró, S. ${ }^{\mathrm{a}}$, Bobo, G. ${ }^{\mathrm{a}}$, Aguiló-Aguayo, I. ${ }^{\mathrm{a}}$

a Postharvest Programme, Institute of Agrifood Research and Technology (IRTA), Lleida, Catalonia 25003, Spain.

${ }^{\mathrm{b}}$ Department of Food Quality and Sensory Analysis, Teagasc Food Research Centre, Ashtown, Dublin 15, Ireland.

\begin{abstract}
Chefs around the world strive to go beyond ordinary and garnish dishes with edible foams and emulsions, generally made using proteins derived from soy or animal sources. However, the increasing number of consumers following a vegan diet has led to a higher demand for novel foods formulated using plant-derived proteins. The current study evaluated the functional properties of proteins obtained by alkaline solubilisation from common pulses. Water- and oilholding capacities varied within the ranges $2.39-6.78$ and $3.46-6.37 \mathrm{~g}$ of water or oil per $\mathrm{g}$ or protein concentrate, respectively. Emulsifying capacity and stability was higher at $\mathrm{pH}$ values 2.0 and 10.0. A similar trend was observed for foaming capacity and stability. Proteins isolated from fava beans showed the highest foaming capacity, calculated as $56.7 \pm 2.9$ and $56.7 \pm 2.7 \%$ when measured at $\mathrm{pH} 2.0$ and 10.0, respectively $(\mathrm{P}<0.05)$. Overall, studied proteins showed potential for their use in edible foams, emulsions and other innovative products.
\end{abstract}

Keywords: Edible foams, emulsions, legumes, technofunctional proteins, vegetable proteins.

\section{Introduction}


The proportion of individuals choosing to follow a vegan diet, mainly because of concerns for animals and health, has increased in recent years - previous studies reported a 350\% increase over the past decade (Hodson \& Earle, 2018). This has led to the development and commercialisation of novel foods that mimic conventional products containing animal-derived proteins such as eggfree mayonnaise, tofu or soya 'milk'.

Chefs around the world strive to go beyond ordinary and garnish dishes with edible foams and emulsions. Most common food dispersions include oil-in-water and water-in-oil emulsions, in which one liquid is dispersed into another liquid in the form of droplets, and foams, in which air bubbles are dispersed in a continuous liquid medium. Commercialisation and consumption of traditional foams such as whipped cream, meringue or mousse is not new. However, over the last two decades, foams have become a part of molecular gastronomy techniques and novel food garnishes such as espresso, beetroot or fish foams have been developed.

Proteins play an important role as surfactants in both edible foams and emulsions. A large number of studies on protein-based emulsions have been published. Proteins derived from milk and egg are the most commonly used food emulsifying agents (Dickinson, 2009). However, proteinstabilised foams are still an underdeveloped field (Jarpa-Parra, 2018). Common proteins used for making edible foams include egg proteins and soy lecithin (Dickinson, 2010). Over the last decade, some studies evaluated the technofunctional properties of non-animal-derived proteins including seaweed (Garcia-Vaquero et al., 2017) or vegetables (Khan et al., 2015). Pulses are excellent sources of numerous nutritional factors including bioaccessible polyphenols (Lafarga et al., 2019) and their consumption has been associated with cholesterol- and lipid-lowering effects in humans, among other positive health outcomes (Jarpa-Parra, 2018). Indeed, several authors highlighted the potential enrichment of foods using, for example, legume flours (Giubert \& Gallo, 2018). Legumes are also rich sources of proteins, which could be used to create innovative foams and emulsions. However, only a limited number of papers evaluated the functional properties of proteins isolated from legumes such as chickpeas, peas or lentils. These are of special interest mainly because of potential allergenicity to soy, which together with peanuts account for the most significant food allergies in the United States and Europe (Cabanillas et al., 2018). 
The aim of the current study was to evaluate the potential of proteins extracted from lentils, cowpeas, fava beans, chickpeas, soybeans, runner beans, beans and peas to be used as surfactants to create different emulsions and foams. Other functional properties studied included waterholding capacity (WHC) and oil-holding capacity (OHC), all of them relevant to food processors and chefs.

\section{Materials and methods}

\section{Protein extraction}

Proteins were extracted following an ultrasound-assisted isoelectric solubilisation-precipitation strategy described by Lafarga et al. (2018). The recovered proteins, shown in Fig. 1, were frozen, freeze-dried using a Cryodos-50 freeze-dryer (Telstar, Barcelona, Spain) and stored at $-20^{\circ} \mathrm{C}$ until further analysis. Freezing temperature was $-50 \pm 2^{\circ} \mathrm{C}$, and drying temperature was kept at $25 \pm 1$ ${ }^{\circ} \mathrm{C}$.

\section{Colour determination}

The colour of the freeze-dried proteins and of the generated emulsions was analysed using a Minolta CR-200 colorimeter (Minolta INC, Tokyo, Japan). The instrument was calibrated with a standard white tile provided by the manufacturer and the D65 illuminant. CIE values were recorded in terms of $L^{*}, a^{*}$ and $b^{*}$. The $L^{*}$ value represent lightness and varies between 0 (black) and 100 (white). The $a^{*}$ value indicates greenness (negative) or redness (positive) while the $b^{*}$ value quantifies blueness (negative) to yellowness (positive). The Chroma $(\mathrm{Ch})$ and hue $\left(h^{o}\right)$ values were calculated as described by McLellan et al. (1995).

\section{Analysis of $\mathrm{pH}$ and water activity}

Freeze-dried proteins were resuspended in distilled water at a concentration of $1 \%(\mathrm{w} / \mathrm{v})$, and the pH was measured using a Basic 20 pH-metre (Crison Instruments S.A., Barcelona, Spain). The water activity (aw) of was measured in triplicate using an AquaLab meter (Decagon Devices Inc., WA, USA) at $22.1 \pm 0.3^{\circ} \mathrm{C}$. 
Water- and oil-holding capacity

WHC and OHC were determined following the methodology described by Garcia-Vaquero et al. (2017). Briefly, freeze-dried proteins were mixed with either water or olive oil at a protein to water or oil ratio of 1:10 (w/v) in a vortex mixer and centrifuged at $10000 \mathrm{~g}$ for $10 \mathrm{~min}$ using a Sigma 3-18 KS centrifuge (Sigma Laborzentrifugen GmbH, Osterode am Harz, Germany). The supernatants obtained were discarded, and the sediments were weighed. WHC and OHC were expressed as $g$ of water or oil held per $g$ of protein.

\section{Emulsifying capacity and emulsion stability}

Two emulsions were prepared in triplicate per protein. One was used to evaluate the emulsifying capacity (EC) and the other was used to calculate colour attributes and to simulate a conventional emulsion preparation. The emulsions and the EC of the isolated proteins were prepared/determined according to the method described by Garcia-Vaquero et al. (2017). To determine the emulsion stability (ES), the prepared emulsions were heated at $85^{\circ} \mathrm{C}$ for $15 \mathrm{~min}$ in a water bath, cooled at room temperature for $10 \mathrm{~min}$ and centrifuged again at 1,100 $\mathrm{g}$ for $5 \mathrm{~min}$. ES was calculated as the percentage of emulsion remaining after heating. The $\mathrm{pH}$ was adjusted using $1 \mathrm{M} \mathrm{HCl}$ or $\mathrm{NaOH}(0.1 \mathrm{M}$ for fine adjustment).

To measure colour parameters and to simulate a conventional preparation, proteins were resuspended in tap water $(\mathrm{pH} 7.66)$ at a concentration of $3 \%(\mathrm{w} / \mathrm{v})$ and the protein solution was homogenised for $30 \mathrm{~s}$ at $1314 \mathrm{~g}$. Olive oil was added to a protein solution to oil ratio of 1:4, and the mixture was homogenised for $120 \mathrm{~s}$ at $1314 \mathrm{~g}$.

\section{Foaming capacity and foam stability}

Foams and the foaming capacity (FC) of the isolated proteins were prepared or determined as described by Lafarga et al. (2018). The FC was calculated as amount of foam generated as a percentage of the initial volume of solution. The $\mathrm{pH}$ was adjusted using $1 \mathrm{M} \mathrm{HCl}$ or $\mathrm{NaOH}(0.1$ 
$\mathrm{M}$ for fine adjustment). Foam stability (FS) was expressed as the percentage of decrease of foam volume over time.

\section{Statistical analysis}

Statistical differences were analysed using analysis of variance (ANOVA) with JMP 13 (SAS Institute Inc., Cary, USA), and results were expressed as the mean of three independent experiments \pm standard deviation (SD). A Tukey pairwise comparison of the means was conducted to determine the differences of the mean values $(P<0.05)$. Bivariate Pearson's correlation analysis was carried out to identify relationships between parameters.

\section{Results and discussion}

Proteins isolated from dried legumes: colour, $\mathrm{pH}$ and water activity

The colour of mayonnaise generally varies between white to pale yellow because they are generally made using egg yolk (or whole egg). Consumers associate this colour range to mayonnaise, and therefore, proteins used to produce egg-free 'mayonnaises' should not affect the products' colour. The $L^{*}$ parameter, which denotes lightness and varies from 0 (black) to 100 (white) of the isolated proteins is shown in Table S1. Values ranged between 51.9 and 80.9 and demonstrate a lighter appearance of, for example, proteins derived from common beans or runner beans when compared to peas or lentils $(\mathrm{P}<0.05)$. This can be clearly seen in Fig. 1 , as proteins with lower $L^{*}$ values are clearly darker when compared to those with higher lightness. Overall, $L^{*}, a^{*}$ and $b^{*}$ values were comparable to those previously reported for proteins derived from pulses including beans (Lafarga et al.,2018), peas (Shevkani \& Singh, 2015), cowpea (GarciaVaquero et al., 2017) and other pulses (Wani et al.,2015). The $h^{o}$ value represents the quality by which we distinguish one colour from another as red, yellow, green, blue or purple, and $C h$ values represent the degree of departure from grey towards pure chromatic colour and are a quantitative indicator of the intensity of a distinctive hue. In the current study, ${ }^{\circ} h$ and $C h$ values ranged between 72.3 and 99.6 and 11.5 and 22.1, respectively, suggesting a higher colour intensity in chickpea-derived proteins when compared to those extracted from common beans or peas $(P<$ 
0.05). Similar $C h$ values were reported previously for proteins extracted from Ganxet common beans calculated as $11.1 \pm 0.1$ (Lafarga et al., 2018). Ch values were also comparable to those reported for other proteins such as seaweed (Garcia-Vaquero et al., 2017).

The $\mathrm{pH}$ and aw values are important for the storage of the products before their industrial application (Table 1). Results obtained suggest that the generated protein-rich powders would be stable during storage as values within this range $(0.180-0.190)$ do not enable microbial growth. In addition, aw values were comparable to those reported in previous studies (Lafarga et al., 2016) and to commercialised powders such as soluble coffee (Schmidt \& Fontana, 2007).
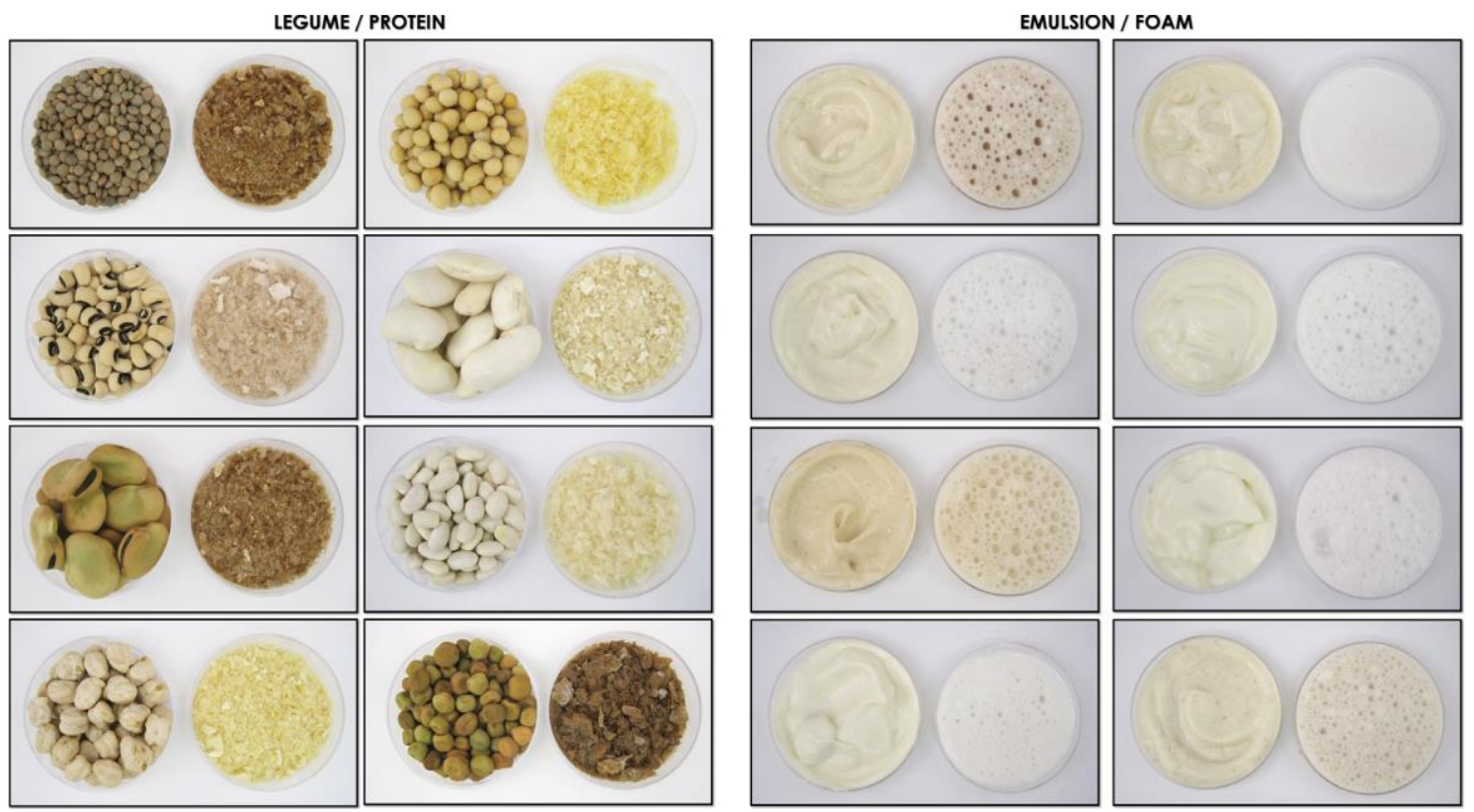

Figure 1. Selected legumes and generated protein isolates, emulsions, and foams. (a) Lentils

(Lens culinaris L.); (b) Cowpeas (Vigna unguiculata L.); (c) fava beans (Vicia fava L.); (d)

Chickpeas (Cicer arietinum L.); (e) Soybeans (Glycine max L.); (f) Runner beans (Phaseolus coccineus L.); (g) Beans (Phaseolus vulgaris L.); and (h) Peas (Pisum sativum L.).

\section{Water- and oil-holding capacities}

Interactions between proteins and both water and oil are important for the food industry because of their effects on flavour and texture (Garcia-Vaquero et al.,2017). Factors affecting WHC and $\mathrm{OHC}$ of proteins include their amino acid composition, protein conformation and surface polarity/hydrophobicity (Yu et al.,2007). High WHC values are important in viscous foods such 
as soups or custards because they allow to imbibe water without dissolution of the protein providing body, thickening and viscosity (Kumar et al.,2014). In turn, high OHC values are desirable for flavour retention and improving palatability of foods (Tiwari et al., 2008), as well as indicative of good emulsion ability.

\begin{tabular}{lllll} 
Table 1 Functional properties of the isolated proteins & & \\
\hline Protein source & WHC $\left(\mathbf{g}\right.$ water $\mathbf{~ g}^{-1}$ of isolate) & OHC $(\mathbf{g}$ oil g & \\
\hline A. Lentil & of isolate) & pH & $\mathbf{a}_{w}$ \\
B. Cowpea & $6.78 \pm 0.09^{\mathrm{A}}$ & $6.37 \pm 0.09^{\mathrm{A}}$ & $5.85 \pm 0.03^{\mathrm{D}}$ & $0.185 \pm 0.002^{\mathrm{A}}$ \\
C. Faba bean & $6.08 \pm 0.12^{\mathrm{C}}$ & $5.83 \pm 0.01^{\mathrm{B}}$ & $5.92 \pm 0.02^{\mathrm{C}}$ & $0.188 \pm 0.003^{\mathrm{A}}$ \\
D. Chickpea & $6.52 \pm 0.05^{\mathrm{B}}$ & $5.09 \pm 0.13^{\mathrm{DE}}$ & $5.96 \pm 0.02^{\mathrm{C}}$ & $0.184 \pm 0.002^{\mathrm{A}}$ \\
E. Soybean & $5.44 \pm 0.11^{\mathrm{D}}$ & $5.37 \pm 0.15^{\mathrm{C}}$ & $5.76 \pm 0.03^{\mathrm{E}}$ & $0.184 \pm 0.005^{\mathrm{A}}$ \\
F. Runner bean & $2.39 \pm 0.11^{\mathrm{E}}$ & $5.37 \pm 0.08^{\mathrm{C}}$ & $6.39 \pm 0.04^{\mathrm{A}}$ & $0.182 \pm 0.004^{\mathrm{A}}$ \\
G. Bean & $5.43 \pm 1.08^{\mathrm{BCD}}$ & $3.46 \pm 0.17^{\mathrm{F}}$ & $5.97 \pm 0.05^{\mathrm{C}}$ & $0.186 \pm 0.003^{\mathrm{A}}$ \\
H. Pea & $5.43 \pm 0.06^{\mathrm{D}}$ & $5.59 \pm 0.34^{\mathrm{BCD}}$ & $5.95 \pm 0.04^{\mathrm{C}}$ & $0.181 \pm 0.003^{\mathrm{A}}$ \\
\hline
\end{tabular}

Different letters in the same column indicate significant differences between samples. The criterion for statistical p̧ignificance was $P<0.05$

In the current study, WHC values ranged between 2.4 and $6.8 \mathrm{~g} \mathrm{~g} \_1$ (Table 1). Differences in WHC values can be attributed to different solubility, protein structures and availability of polar amino acids which have been shown to be primary sites for water interaction of proteins (Li et al., 2010). These values were higher than those reported for proteins derived from other seeds such as Ganxet beans (Lafarga et al., 2018), mung beans (Li et al., 2010) or hemp seeds (Hadnađev, et al., 2018). Lower WHC values were also reported for proteins derived from seaweed (Kumar et al., 2014) or peanut (Yu et al., 2007). However, results were comparable to those reported by Wani et al. (2015), who reported that the WHC of 16 varieties of mung beans ranged between 5.34 and $5.85 \mathrm{~g} \mathrm{~g}^{-1}$. In this study, $\mathrm{OHC}$ values ranged between 3.5 and $6.4 \mathrm{~g} \mathrm{~g}^{-1}$. Similar results were observed by Wani et al. (2015), who calculated the OHC of mung beanderived proteins within the range 5.8-6.9 $\mathrm{g} \mathrm{g}^{-1}$ and by Adebowale et al. (2011), who observed OHC between 6.7 and 7.9 for Bambara groundnut protein isolates. When compared to egg white protein, commonly employed in traditional kitchen recipes, the values reported for WHC and OHC range from 0.90 to $4.5 \mathrm{~g} \mathrm{~g}^{-1}$ and from 0.92 to $4.22 \mathrm{~g} \mathrm{~g}^{-1}$, respectively (Segura-Campos et al., 2013).

\section{Emulsifying properties}

Good emulsifying properties are desired for the manufacture of vegetable-derived beverages or meat analogues, which are hot trends in the food industry (Tiwari et al., 2008). In addition, chefs 
could improve the presentation of dishes, suitable for vegans and vegetarian consumers, while adding different textures and flavours, by incorporating novel emulsions into their recipes. Emulsifying properties are shown in Fig. 2. Both EC and ES were significantly affected by the $\mathrm{pH}(P<0.05)$. At $\mathrm{pH} 2.0$ and 10.0, the EC of all the studied proteins was approximately $80 \%$. Emulsions made at these $\mathrm{pH}$ values were also more stable, as higher ES values were observed at pH 2.0 and $10.0(\mathrm{P}<0.05)$. Results were in line with those reported by Tirgar et al. (2017), who calculated the EC of flaxseed proteins, isolated by isoelectric precipitation, between $80 \%$ and 90\%. Results were also comparable with those observed by Garcia-Vaquero et al. (2017) using algae-derived proteins. When the $\mathrm{pH}$ value was shifted to 4.0 and 6.0, the EC values significantly decreased and ranged between $10 \%$ and $40 \%$. This was probably caused by the extraction methodology followed, which could have led to low solubility at these $\mathrm{pH}$ values and to the formation of protein aggregates which hide the hydrophobic groups of the proteins, reducing their EC. Contrarily, at extreme pH's the protein structure is unfolded, leading to an exposure of buried hydrophobic groups and protein disaggregation, which would facilitate establishing hydrophilic and lipophilic interactions between the aqueous and the lipid phases.

This does not mean that these proteins cannot be used for creating emulsions, as for example, emulsions shown in Fig. 1 were made at pH 7.66 (with different water:oil ratio, homogenisation time and protein concentration). At $\mathrm{pH}$ 8.0, significant differences were observed between different proteins $(P<0.05)$. For example, no differences were observed between the EC of cowpea-derived proteins at $\mathrm{pH}$ values 8.0 and 10.0, while the EC of chickpea-derived proteins at pH 8.0 was significantly lower when compared to that measured at $\mathrm{pH} 10.0(P<0.05)$. Similar results were observed for soybean-, pea- and common bean-derived proteins $(P<0.05)$. Lafarga et al. (2018) recently reported a significant decrease in the EC of proteins derived from common beans at $\mathrm{pH} 4.0$, when compared to that measured at $\mathrm{pH}$ 8.0. Tirgar et al. (2017) recently suggested that the protein extraction strategy greatly influences the composition and functional properties of protein concentrates. In this case, the extraction method employed enriches those proteins with a very low solubility at slightly acid $\mathrm{pH}$ values, since the precipitation step was carried out at a value of 5.5. Therefore, evaluating other extraction alternatives, such as controlled enzymatic 
extractions could lead to increased emulsifying properties. In addition, protein pre-treatments such as enzymatic hydrolysis, heating or high- pressure processing could also result in improved functional properties. For example, Chao et al. (2018) recently reported enhanced FC and emulsion formation when pea proteins were subjected to high hydrostatic pressure, since it mimics the effect of extreme $\mathrm{pH}$ values, leading to protein unfolding.
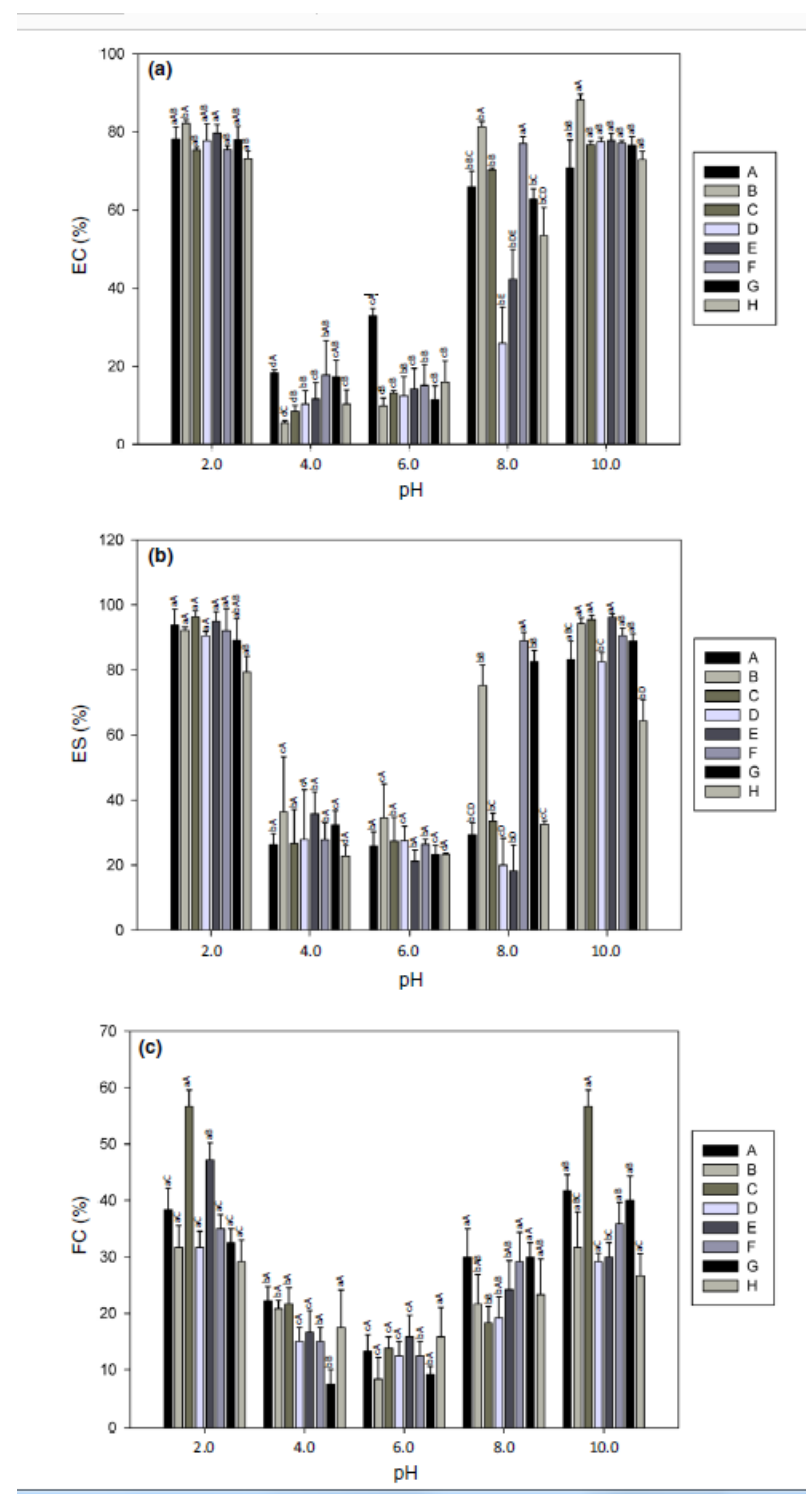

Figure 2. (a) Emulsifying capacity, (b) emulsion stability, and (c) foaming capacity of selected legume-derived proteins. Emulsions or foams made using proteins extracted from: (a) Lentils; (b) Cowpeas; (c) Fava beans; (d) Chickpeas; (e) Soybeans; (f) Runner beans; (g) Beans; and (h) Peas. Values represent the mean of three independent studies $\pm S D$. Different capital letters indicate significant differences in emulsifying/foaming capacity or stability for emulsions/foams 
made using different proteins at the same $p H$. Lower case letters indicate significant differences in emulsifying/foaming capacity or stability for emulsions/foams made using the same protein at different $p H$ values. The criterion for statistical significance was $P<0.05$.

Figure 1 shows, as an example, the emulsions generated using the isolated proteins, olive oil, and tap water (pH 7.66). Colour attributes of the generated emulsions are listed in Table S1. The $L^{*}$ values of the emulsions ranged between 80 and 90 for all the studied proteins. The highest luminosity was observed for emulsions made using runner beans and common beans $(P<0.05)$. A positive correlation was observed between the luminosity of the dried protein powder and the emulsion luminosity $(0.792 ; P<0.001)$, as well as for the $a^{*}$ parameter of the emulsions and protein powders $(0.724 ; P<0.001)$. Protein a* values were also positively correlated with emulsion $a^{*}$ values $(0.591, P<0.001)$. Although differences were observed between the $C h$ values of the generated emulsions, all ranged between 9 and 15. Differences between the colour of the different emulsions can be seen in Fig. 1.

\section{Foaming capacity}

The capacity of proteins to form stable foams is important in the production of a variety of foods, as these contribute to the uniform distribution of fine air cells in the structure of foods. Foams are formed when proteins diffuse and adsorb the air-water interface, reducing the surface tension and forming an interfacial film around the air bubbles (Jarpa-Parra, 2018). The FC of the studied proteins at different $\mathrm{pH}$ values is shown in Fig. 2. Proteins isolated from fava beans showed the highest FC values which were calculated as $56.7 \pm 2.9$ and $56.7 \pm 2.7 \%$ when measured at $\mathrm{pH} 2.0$ and 10.0, respectively $(P<0.05)$. FC values were in line with those obtained for other protein sources such as common beans (Lafarga et al.,2018), cowpeas (Ragab et al., 2004) and mung beans ( $\mathrm{Li}$ et al., 2010). In the present study, $\mathrm{FC}$ was higher at $\mathrm{pH}$ values 2.0 and $10.0(P<0.05)$. Previous studies also observed higher FC values at extreme pH values such as 2.0 (Kumar et al., 2014) and 10.0 (Garcia-Vaquero et al., 2017). The observed higher FC values at extreme pH values was attributed to solubility and the increased net charges on the protein, which could have weakened the hydrophobic interactions but increased the flexibility of the protein (Ragab et al., 
2004). Structural properties of proteins can also affect FC, and this could explain the higher FC values for proteins derived from fava beans and soybeans $(P<0.05)$. Moreover, the stability of the foams during a 30 min period is shown in Figure S1. The FS was significantly affected by time $\mathrm{pH}(P<0.001)$, time $(P<0.001)$ and $\mathrm{pH}^{*}$ time interactions $(P<0.001)$. Overall, the generated foams showed lower FS at $\mathrm{pH}$ values ranging from 4.0 to $8.0(P<0.05)$. Similar results were obtained previously at these same pH values (Khalid et al., 2003; Ragab et al., 2004; GarciaVaquero et al., 2017; Lafarga et al., 2018). Results demonstrate that not only the FC but also the stability of the foams, made using legume-derived proteins extracted using alkaline solubilisation, are higher at extreme $\mathrm{pH}$ values.

\section{Conclusions}

The foam and emulsion stabilising properties of proteins isolated from pulses were investigated. The observed WHC and OHC values were in line with those reported in previous studies for plantand animal-derived proteins suggesting the potential utilisation of pulse-derived proteins to improve thickening and viscosity of liquid foods. The EC and FC of the isolated proteins were higher at extreme $\mathrm{pH}$ values, which are not applicable for food formulations. However, at milder $\mathrm{pH}$ conditions, the isolated proteins still showed potential applications for developing novel foams and emulsions and results compared well with those reported for proteins derived from other foods.

Studied proteins showed potential for their use in the manufacture of edible foams and emulsions, which could lead to the development of a large number of innovative products suitable for those who decide not to consume animal-derived foods.

\section{Acknowledgments}

Authors would like to acknowledge the CERCA Programme of Generalitat de Catalunya and the Spanish Ministry of Economy, Industry, and Competitiveness (FJCI-2016-29541; RYC-201619949).

\section{Conflict of interest}

The authors declare no conflict of interests. 


\section{References}

Adebowale, Y.A., Schwarzenbolz, U. \& Henle, T. (2011). Protein isolates from Bambara groundnut (Voandzeia Subterranean L.): Chemical characterization and functional properties. International Journal of Food Properties, 14, 758-775.

Cabanillas, B., Jappe, U. \& Novak, N. (2018). Allergy to peanut, soybean, and other legumes: recent advances in allergen characterization, stability to processing and ige crossreactivity. Molecular nutrition \& food research, 62, 1700446.

Chao, D., Jung, S. \& Aluko, R.E. (2018). Physicochemical and functional properties of high pressure-treated isolated pea protein. Innovative Food Science \& Emerging Technologies, $45,179-185$.

Dickinson, E. (2009). Hydrocolloids as emulsifiers and emulsion stabilizers. Food Hydrocolloids, $23,1473-1482$.

Dickinson, E. (2010). Food emulsions and foams: Stabilization by particles. Current Opinion in Colloid \& Interface Science, 15, 40- 49.

Garcia-Vaquero, M., Lopez-Alonso, M. \& Hayes, M. (2017). Assessment of the functional properties of protein extracted from the brown seaweed Himanthalia elongata (Linnaeus) S. F. Gray. Food Research International, 99, 971-978.

Giubert, G. \& Gallo, A. (2018). Reducing the glycaemic index and increasing the slowly digestible starch content in gluten-free cereal based foods: a review. International Journal of Food Science and Technology, 53, 50-60.

Hadnađev, M., Dapčević-Hadnađev, T., Lazaridou, et al. (2018). Hempseed meal protein isolates prepared by different isolation techniques. Part I. physicochemical properties. Food hydrocolloids, 79, 526-533.

Hodson, G. \& Earle, M. (2018). Conservatism predicts lapses from vegetarian/vegan diets to meat consumption (through lower social justice concerns and social support). Appetite, 120, $75-81$. 
Jarpa-Parra, M. (2018). Lentil protein: a review of functional properties and food application. An overview of lentil protein functionality. International Journal of Food Science and Technology, 53, 892-903.

Khalid, E., Babiker, E. \& Tinay, A.E. (2003). Solubility and functional properties of sesame seed proteins as influenced by $\mathrm{pH}$ and/or salt concentration. Food Chemistry, 82, 361-366.

Khan, N.M., Mu, T.-H., Ali, F., et al. (2015). Effects of high hydrostatic pressure on emulsifying properties of sweet potato protein in model protein-hydrocolloids system. Food Chemistry, 169, 448- 454.

Kumar, K.S., Ganesan, K., Selvaraj, K. \& Rao, P.S. (2014). Studies on the functional properties of protein concentrate of Kappaphycus alvarezii (Doty) Doty-An edible seaweed. Food Chemistry, 153, 353-360.

Lafarga, T., Rai, D.K., O'connor, P. \& Hayes, M. (2016). Generation of bioactive hydrolysates and peptides from bovine hemoglobin with in vitro renin, angiotensin-I-converting enzyme and dipeptidyl peptidase-IV inhibitory activities. Journal of Food Biochemistry, $40,673-685$.

Lafarga, T., Álvarez, C., Bobo, G. \& Aguiló-Aguayo, I. (2018). Characterization of functional properties of proteins from Ganxet beans (Phaseolus vulgaris L. var. Ganxet) isolated using an ultrasound-assisted methodology. LWT, 98, 106-112.

Lafarga, T., Villaró, S., Bobo, G., Simó, J. \& Aguiló-Aguayo, I. (2019). Bioaccessibility and antioxidant activity of phenolic compounds in cooked pulses. International Journal of Food Science and Technology, 54, 1816-1823.

Li, W., Shu, C., Yan, S. \& Shen, Q. (2010). Characteristics of sixteen mung bean cultivars and their protein isolates. International Journal of Food Science \& Technology, 45, 12051211.

McLellan, M.R., Lind, L.R. \& Kime, R.W. (1995). Hue angle determinations and statistical analysis for multiquadrant hunter $L, a, b$ data. Journal of Food Quality, 18, 235-240. 
Ragab, D.M., Babiker, E.E. \& Eltinay, A.H. (2004). Fractionation, solubility and functional properties of cowpea (Vigna unguiculata) proteins as affected by $\mathrm{pH}$ and/or salt concentration. Food Chemistry, 84, 207-212.

Schmidt, S. \& Fontana, A. (2007). Water activity values of selected food ingredients and products. In: Water activity in foods-fundamentals and applications (edited by G. BarbosaCánovas, F. Schmidt \& T. Labuza). Pp. 413-414. Blackwell Publishing and the Institute of Food Technologists: Chicago, IL.

Segura-Campos, M., Pérez-Hernández, R., Chel-Guerrero, L., Castellanos-Ruelas, A., GallegosTintoré, S. \& Betancur-Ancona, D. (2013). Physicochemical and functional properties of dehydrated Japanese quail (Coturnix japonica) egg white. Food and Nutrition Sciences, 4, 289.

Shevkani, K. \& Singh, N. (2015). Relationship between protein characteristics and film-forming properties of kidney bean, field pea and amaranth protein isolates. International Journal of Food Science \& Technology, 50, 1033-1043.

Tirgar, M., Silcock, P., Carne, A. \& Birch, E.J. (2017). Effect of extraction method on functional properties of flaxseed protein concentrates. Food Chemistry, 215, 417-424.

Tiwari, B., Tiwari, U., Jagan Mohan, R. \& Alagusundaram, K. (2008). Effect of various pretreatments on functional, physiochemical, and cooking properties of pigeon pea (Cajanus cajan L). Food Science and Technology International, 14, 487-495.

Wani, I.A., Sogi, D.S., Shivhare, U.S. \& Gill, B.S. (2015). Physicochemical and functional properties of native and hydrolyzed kidney bean (Phaseolus vulgaris L.) protein isolates. Food Research International, 76, 11-18.

Yu, J., Ahmedna, M. \& Goktepe, I. (2007). Peanut protein concentrate: Production and functional properties as affected by processing. Food Chemistry, 103, 121-129. 